\title{
Patrones funerarios en SAN José de SAMIRIA, LORETO Y SUS VARIACIONES A TRAVÉS DEL TIEMPO.
}

\author{
Eva Ruíz dEL ÁGuILA.
}

El presente artículo está referido al tema de los patrones funerarios de las poblaciones amazónicas pertenecientes a la familia lingüística Tupí Guaraní y sus variaciones a través del tiempo, quienes se asentaron a lo largo de la cuenca del Río Samiria desde el siglo XVI hasta la actualidad. Para lo cual se contrastó la información etnohistórica y etnográfica con la evidencia arqueológica. Estos grupos están representados por los Omaguas, Cocamas y Cocamilla.

The present article deals with the study of the funeral patterns and its variations through time of the Amazonían populations pertaining to the Tupí Guaraní linguistic family, These populations settled throughout the Samiria river basin from XVI century to the present time. For this study ethnohistoric and ethnographic information were contrasted with the archaeological evidence. The analysis reveals that the social groups of Omaguas, Cocamas and Cocamillas are represented in the funerary contexts of the area. 
El tema a tratar se desarrolló a partir de las excavaciones realizadas en un cementerio arqueológico relacionado al grupo cultural Omagua del siglo XVI, en el sitio conocido como El Zapotal ubicado en la comunidad de San José de Samiria, departamento de Loreto, como parte del Proyecto de Arqueología Amazónica dirigido por el Lic. Daniel Morales Chocano.

Los Omaguas pertenecientes a la familia lingüística Tupi Guaraní, en la actualidad se encuentran culturalmente desaparecidos, siendo sus más cercanos descendientes los Cocama y Cocamillas, quienes han sobrevivido a los efectos del contacto con la cultura occidental, aunque claro está con variaciones al interior de su cultura.

Los patrones funerarios tratados en la investigación arqueológica de la selva peruana ha sido poco y fragmentario debido a que resulta difícil la conservación del material orgánico, en este caso óseo, dentro de la Amazonía debido a sus características medioambientales: lluvias continuas y grandes áreas inundadas durante gran parte del año.

En contraste a la evidencia arqueológica, los informes etnohistóricos y etnográficos que tratan sobre los modos de vida y costumbres de estas poblaciones son abundantes, por lo que la revisión de dichas fuentes es de mucha importancia no sólo porque nos permiten compararlos con los datos obtenidos durante las excavaciones sino que además nos ayudan durante la interpretación de los materiales recuperados.

Las prácticas mortuorias de una sociedad nos permiten inferir aspectos sobre el concepto que éstas tienen sobre la muerte y cual es su comportamiento en torno a ello. En la mayoría de los casos este comportamiento se evidencia en los entierros, y que para la arqueología significa un contexto, normalmente sellado, es decir un conjunto de objetos coetáneos e interrelacionados. Donde el contexto funerario implica tres componentes: la estructura funeraria, el individuo y su tratamiento, y los objetos asociados. (Kaulicke, 1997: III)

Siendo el cementerio el grupo de contextos funerarios dispuestos en un determinado espacio. Al realizar profundas comparaciones de los contextos funerarios en un cementerio y de cómo éstos se disponen podremos determinar el patrón funerario.

Pues bien, por tratarse de poblaciones de la época de contacto con la cultura occidental primeramente haremos una revisión de la información etnohistórica y etnográfica relacionadas a estas antiguas poblaciones para luego contrastarlas con la evidencia arqueológica. 


\section{Primeros ingresos a la Amazonía Peruana}

Durante el siglo XVI se realizaron los primeros ingresos de españoles a las tierras amazónicas que actualmente se encuentran dentro del territorio peruano.

Los escritos dejados por ellos nos relatan los diversos acontecimientos que se suscitaron durante sus viajes, no sólo relacionados a las dificultades que tuvieron que afrontar al ingresar a un territorio geográficamente desconocido para ellos, sino además, el hecho de encontrarse con las poblaciones nativas que habitaban dichos territorios al momento de su ingreso y con las cuales tuvieron una serie de enfrentamientos.

Los viajes hacia esas regiones durante ese siglo no tenían otro fin que el de «descubrir» minerales como el oro (la búsqueda del Dorado) o de uso comestible como la canela (el viaje de Gonzalo Pizarro y Francisco de Orellana), que les permitiera a los españoles enriquecerse en breve plazo, por lo que su interés sólo se centraba en la explotación de los recursos que esperaban "descubrir», sin preocuparles la población local y el hecho de establecer algún tipo de relación que los beneficiara a ambos. Mas bien, cuando establecían relaciones con un grupo sobre todo durante los primeros viajes- era sólo para que los españoles pudieran garantizar su seguridad durante su permanencia en ese lugar, es decir, se mostraban amigables sólo cuando les convenía hacerlo. Pues no olvidemos que durante esa época los europeos consideraban a los nativos de estos lugares como seres inferiores, es decir, no eran personas propiamente dichas.

Es en ese siglo donde encontramos las primeras referencias sobre los Omagua, mencionándose que se trataba de un grupo mejor organizado y mucho más grande que los otros, sin profundizar en otras características culturales debido a la naturaleza del viaje realizado en aquel momento, tal como se desprende de los relatos de Fray Gaspar de Carvajal, cuando en 1542 acompañó a Orellana en su descenso por el Amazonas:

«esto era ya en el señorío y tierra de Omagua, y por ser los pueblos tantos y tan grandes y haber tanta gente, no quiso el Capitán tomar puerto...» (s.f., p. 246)

Mientras que Juan Salinas de Loyola, quien vio a un grupo de nativos Omagua durante su expedición en el Ucayali a mediados del Siglo XVI, hace una descripción más detallada de ellos:

«En esta distancia topé y descubrí muchas provincias de gente de mucha razón y policía, de ropa de algodón muy pintada, así de pincel como labradas; joyas de oro y plata, de que adornaban sus personas...» (Stocks 1981:43). 


\section{El sistema de Misiones durante la Colonia}

A diferencia del siglo XVI, se tiene mucha información sobre los usos y costumbres de las poblaciones amazónicas durante el siglo XVII escrita por los misioneros que llegaron a estas tierras para cumplir la tarea de evangelizar o cristianizar a las poblaciones nativas, a quienes llamaban «infieles».

El actual departamento de Loreto pertenecía a la Misión Jesuítica de Maynas durante la época colonial.

La llegada de los misioneros jesuitas a la región se inició en el año 1636, luego de producida una gran rebelión que tuvo como protagonistas principales a la población indígena contra los encomenderos y soldados españoles que en aquel entonces se encontraban ocupando la región de Maynas. La causa de dicha rebelión se debió a los continuos maltratos y abusos que cometían los españoles contra los pobladores nativos.

La presencia de los misioneros jesuitas se prolongó hasta el año 1717, año en el cual fueron expulsados por los gobiernos coloniales en América.

Durante el periodo misional jesuítico, la modalidad de asentamiento propuesta para la evangelización fue la reducción o el establecimiento de poblados, conceptualmente permanentes, en los cuales debía congregarse o «reducirse» a los pobladores de las distintas etnias amazónicas para poder desarrollar una cristianización más profunda y permanente de sus habitantes. (Negro, 1999: 282)

Estos traslados masivos de pobladores tuvieron una terrible consecuencia entre los indígenas, tales como el desarraigo cultural, producido paralelamente a un fuerte proceso de aculturación diferente al propio, así como la convivencia de etnias con diferentes estructuras sociales y políticas, que produjo la desaparición de muchas de éstas como unidades culturales. (Negro, 1999: 281)

Pero con el establecimiento de las reducciones también se agudizaron en la región diversas epidemias que arrasaron con la mayor parte de la población indígena, la que no contaba con defensas frente a estas nuevas enfermedades traídas por los europeos.

El sistema de reducciones tuvo implicancias funestas dentro de la población nativa, que vio reducida su población en espacios de tiempo muy corto, donde las muertes eran de carácter masivo.

Estas muertes masivas, que no tenían nada que ver con hechos de guerras interétnicas a las que los grupos nativos amazónicos estaban acostumbrados, provocó en ellos cambios ideológicos culturales muy rápidos como se desprende del trabajo de Stocks(1981:67): 
«...los nativos no-bautizados hacían cola para bautizarse, esperando que este acto los salvara, y así el Padre Lucero bautizó en quince días, a 600 nativos, que pronto se murieron...»

Pero los cambios no sólo afectaron a los nativos a nivel ideológico, sino que además influyó mucho en la realización de sus prácticas culturales en torno al tema de la muerte, las que se dejaron muchas veces de lado ante la aparición de las epidemias, tal como lo menciona el Padre Francisco de Figueroa (1986:198):

«Era cosa horrorosa ver los enfermos y cuerpos muertos por los arenales, á donde en ranchillos se abian retirado, comidos de gallinacos y otras aves y expuestos á que el rio con sus crecientes barriesse como barrió, con los huesos. Por estas causas ha benido esta reducción á gran diminucion.»

Sin embargo cuando no se producían estas muertes masivas, los nativos continuaban ejerciendo sus ritos funerarios cuando fallecía algún miembro de su comunidad, pues así también lo refiere el Padre Figueroa (1986:286-288):

"A sus difuntos los entierran con sus alhajas en las mesmas casas donde todos viben, sin que les cause horror el tenerlos en vna posada, ni temor el dormir inmediatos ó encima de sus sepulturas. Los severos solian meter el cuerpo en vna tinaja grande, tan aprisa que, dando gemidos y alaridos á las vltimas boqueadas del emfermo le tapaban la boca, y luego lo ataban doblándolo, juntándole las rodillas con el pecho; lo metían en la tinaja, que estaba ya preparada y puesta en el hondo de vna sepultura redonda y honda, donde lo colocaban, tapando la boca de la tinaja con otra que la tenian dispuesta y ajustada al propósito; y dejándolo en essa ataud, le echaban la tierra encima. Los cocamas tambien los enterraban al modo dicho, en ollas grandes. De la mesma manera los cocamillas y otros. Los roamaynas hacen la sepultura al modo ordinario: cuelgan en ella vna hamaca, y en ésta al cuerpo difunto. Tapan la boca de la sepultura con tablas hechas de troncos picados de palmas, y encima deste tablado ó barbacoa hechan y amontonan la tierra, dejando al cuerpo péndulo tendido en la hamaca en el hueco de la sepultura. Assí lo dejan el tiempo que tienen observado [ser] bastante á consumírsele la carne. Después lo desentierran, y limpiando los huesos los meten en una tinaja mediana, angosta y larga, pintada y formando en ella un mascaron del mesmo barro. Bien tapada la boca de la tinaja, tienen assí los huesos en sus casas, donde varias veces he visto hileras destos sepulcros; en ellos los lleban de vnas partes á otras, guardándolos hasta tanto tiempo, que parece es un año; entonces entierran las tinajas con su osamenta para olvidar á sus difuntos. Los cocamas vsaban también el transportar los huesos de sus difuntos en tinajas al modo dicho, haciendo vna gran bebida, que llaman de enjugar las lágrimas, y son sus quitapesares de cualquier mal y tristeza. Y éste es como su cavo de año, en que al desenterrar los huesos los parientes lloran, los demas cantan y bailan, y volviendo después á enterrarlos se olvidan de todo, aun de los nombres de los difuntos». 


\section{Referencias Etnográficas de los Siglos XIX y XX}

Toda esta descripción que nos presenta el Padre Figueroa es similar a aquellas referencias etnográficas de los siglos posteriores, pues como lo menciona Rosa Fung (1982:121-122) , Steward y Metraux (1948), resumieron la información para Perú y Ecuador, concerniente al tratamiento de los cadáveres entre los diferentes grupos etnolinguísticos amazónicos y señalaron la cremación, los entierros en urnas, en canoas o debajo del suelo, ya sea dentro o fuera de las casas, y el endocanibalismo, como prácticas funerarias muy comunes entre estos grupos.

El Padre Castrucci y Vernaza en su visita que hizo a los Jíbaro del Pastaza en 1845, describe que momificaban a los cadáveres asándolos a fuego lento y mucho humo. Los hombres eran enterrados con sus armas, una tinaja de masato y plátano, mientras que las mujeres con sus adornos de dientes de mono, una tinaja de masato, yuca y plátanos. Los párvulos, al lado de un pequeño recipiente lleno de leche materna. (Raimondi, 1879)

La narración epistolar del Padre Vidal de su expedición al Zamora, a fines del siglo XIX, informa que cuando un infante moría, le doblaban mientras aún su cuerpo estaba caliente y era colocado en una vasija de barro que enterraban en el suelo cerca de la casa.

En 1930, Günter Tessman, en su obra «Los Indígenas del Perú Nororiental», describe a los Omagua, indicando sus rasgos culturales en forma detallada, información obtenida según él, de uno de los últimos Omagua de sangre pura. En su obra hace referencia al tipo de vestimenta, vivienda, alimentación, etc. Con respecto a la muerte y formas de entierro, Tessman refiere: «Según Martius, en tiempos antiguos «los líderes y padres de familia» eran sepultados en vasijas de barro dentro de la choza».

Steward y Metraux (1948) mencionan que los Andoas, Awishira y Roamanina han practicado el enterramiento secundario en urnas.

Las urnas de los Roamaina son vasijas antropomorfas y de acuerdo a los datos de Tessman (1930) esta clase de entierros se circunscribían a los hombres, mientras que los cadáveres de las mujeres eran sepultados debajo de los pisos de las casas.

Porras Barrenechea en 1945, menciona que los Maynas disponían de los muertos con todos sus bienes y rompían los objetos que usaron como ollas y demás recipientes de arcilla. Luego quemaban sus viviendas. 


\section{La evidencia arqueológica}

a) Ubicación

La comunidad de San José de Samiria se encuentra ubicada dentro de la Reserva Nacional Pacaya-Samiria, en el departamento de Loreto, al nororiente peruano.

\section{b) Características medioambientales}

La Reserva Nacional Pacaya-Samiria constituye el área de bosque inundable o «várzea» protegida más extensa de la Amazonía, por lo que el sitio de San José de Samiria permanece inundado durante gran parte del año excepto algunas zonas elevadas denominadas restingas.

Justamente las excavaciones que realizamos se ubicaron en un área de restinga a la que los pobladores de San José de Samiria llaman El Zapotal y que usan para el sembrío de árboles frutales como el zapote, de allí su nombre. Junto a El Zapotal se halla la laguna Yarinacocha, fuente de gran variedad de peces.

La temperatura oscila entre $20^{\circ}$ y $30^{\circ} \mathrm{C}$, durante todo el año, aunque en algunas temporadas durante los meses de junio y julio desciende a $15^{\circ} \mathrm{C}$, denominándose a este fenómeno «friaje».

\section{c) Desarrollo de las excavaciones}

Durante la temporada de trabajo de campo realizada entre los meses de septiembre y octubre del año 2002 se excavaron tres áreas en el lugar denominado El Zapotal, correspondiéndome la excavación del Área 01, mientras que las Áreas 02 y 03 fueron excavadas por los arqueólogos Daniel Morales y Araceli Rivera.

Para ubicar estas áreas de excavación se tomó en cuenta la información obtenida de los trabajos de la temporada realizada en el año 2001, periodo en el cual las excavaciones se orientaron a dimensionar los asentamientos y recuperar los contextos asociados. Para ello se excavaron una trinchera en forma de «L» de aproximadamente $5 \mathrm{~m}$. de lado y cuadrículas pequeñas de $1 \times 1 \mathrm{~m}$., distribuidas a lo largo de toda la restinga y separadas entre sí cada 10 y $20 \mathrm{~m}$., manteniendo un eje Norte-Sur.

Es así que durante la temporada de campo del año 2002 las tres áreas de excavación fueron ubicadas en la parte más elevada del sitio, a donde las aguas de la laguna Yarinacocha no llegan cuando comienza el invierno, periodo en el cual el nivel de dicha laguna aumenta. 


\section{d) Descripción del Área 01}

El Área 01 fue ubicada a continuación de la trinchera en forma de «L» excavada durante la temporada 2001, la cual rindió evidencias de contextos funerarios y se encuentra en uno de los puntos más altos de la restinga.

El Área 01 presentó una forma cuadrangular y sus dimensiones fueron de 5x5 m., orientándose en dirección Norte (ver foto 1). La superficie se encontraba cubierta de vegetación de aproximadamente $30 \mathrm{~cm}$. de alto, la que fue retirada para iniciar las excavaciones.

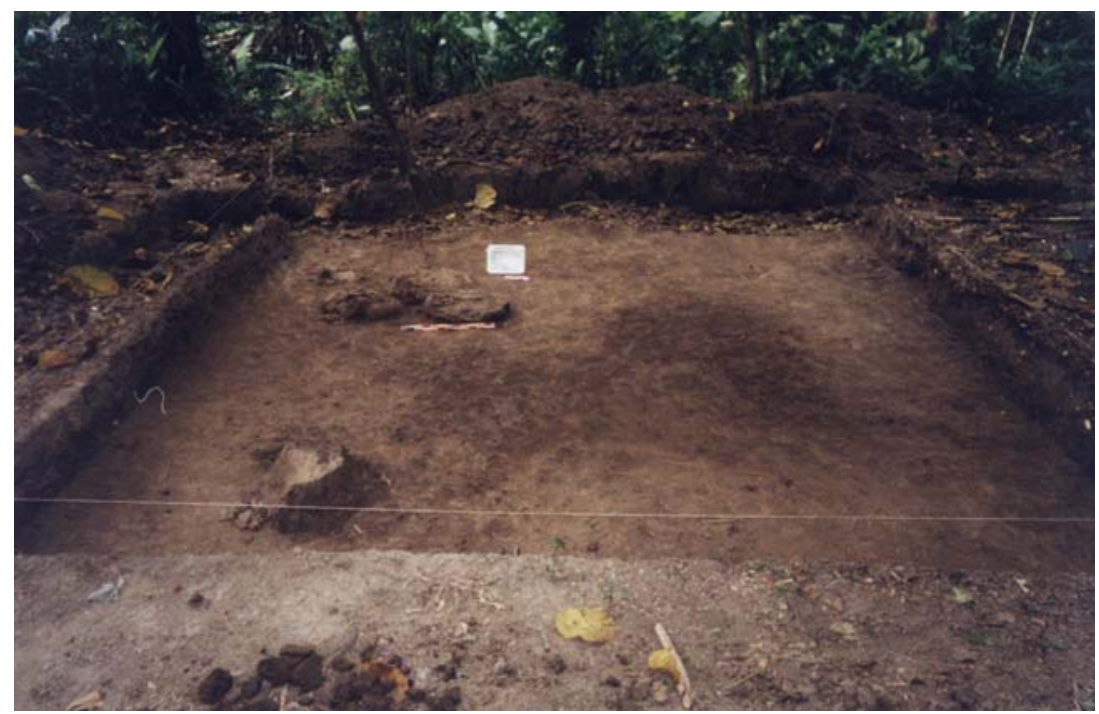

Foto 1.

Vista del Área 01

\section{e) Material cultural recuperado}

El material cultural recuperado de las excavaciones estuvo conformado por abundante fragmentería de cerámica; vasijas completas e incompletas, muchas de las cuales contenían restos óseos humanos; «piruros» de cerámica (instrumentos para el hilado); y en mínima cantidad, material lítico en la forma de cantos rodados muy pequeños, así como también material óseo animal.

Para el registro de los materiales recuperados se usó las categorías de Entierro y Hallazgo. Como Entierro nos referimos a aquel contexto en el que estuvieron presentes los restos óseos de uno o más individuos humanos, sea que estuviesen o no al interior de una urna de cerámica. 
Como Hallazgo nos referimos a aquel contexto consistente de vasijas completas o incompletas que no contenían individuos, así como también para referirnos a otros objetos de distinta naturaleza tales como lítico y óseo animal que se encontraban dispuestos de manera particular.

Los contextos asociados que fueron apareciendo durante el proceso de excavación no fueron retirados al instante, sino que se fueron dejando sobre una matriz, excavándose alrededor, para así poder definir mejor la relación que guardaban entre sí.

Durante la excavación se registraron 27 contextos denominados Entierros y que fueron enumerados de acuerdo al orden en el que fueron apareciendo. Así mismo, se registraron 10 contextos denominados Hallazgos.

\section{f) Distribución espacial de los materiales}

Los Entierros, Hallazgos y fragmentería de cerámica se encontraron distribuidos en toda el área excavada (ver foto 2).

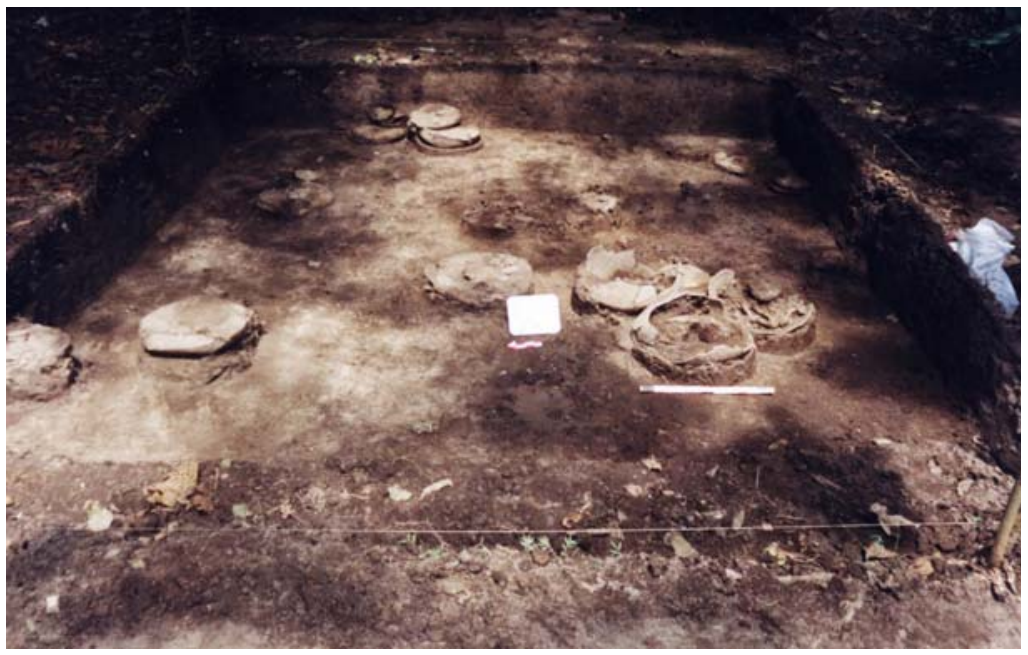

Foto 2.

Vista del Área 01 y los contextos funerarios

En la mayoría de los casos se encontraron formando conjuntos y sólo algunos de manera individual. Entre los que se encontraban formando conjuntos se tienen a aquellos agrupados en el mismo nivel, a los que denominamos Contextos de Distribución Horizontal (ver foto 3) y a aquellos que se encontraban colocados unos sobre otros los denominamos Contextos de Distribución Vertical (ver foto 4). 


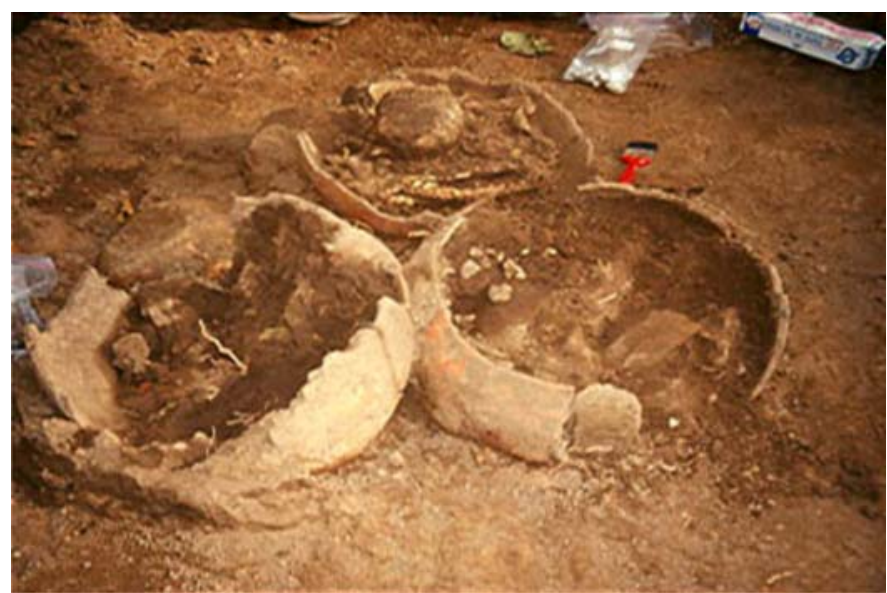

\section{Foto 3.}

Contextos de Distribución Horizontal

(Fuente: Daniel Morales)

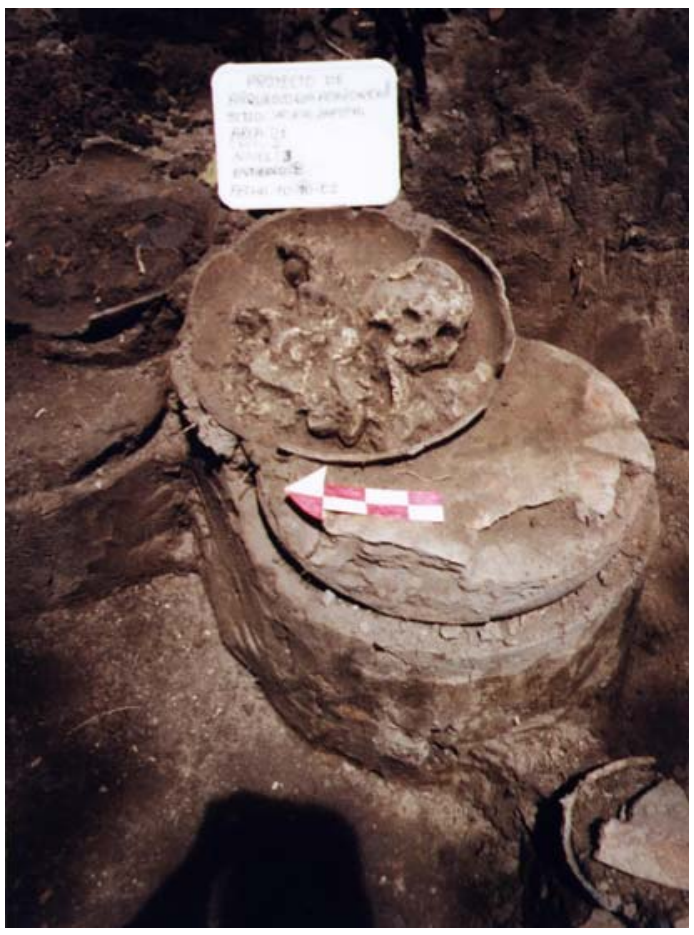

Foto 4.

Contextos de Distribución Vertical 


\section{Tipos de contextos}

\section{funerarios recuperados y tratamiento del individuo}

\section{a) Contextos funerarios}

Dentro del área excavada se recuperaron dos tipos de contextos funerarios: Primario y Secundario, siendo este último el tipo más predominante.

- $\quad$ Contexto Funerario de Tipo Primario: Este tipo de contexto se caracteriza porque el individuo al ser enterrado no sufrió alteraciones del cuerpo de carácter cultural, es decir, el esqueleto no fue desarticulado, observándose una conexión anatómica correcta.

De toda la muestra recuperada sólo uno de los contextos fue de este tipo y que a diferencia de los otros contextos el individuo no fue depositado dentro de una urna, sino que fue colocado directamente sobre el suelo. Este entierro se encontró en el nivel más profundo de la excavación y fue el Entierro 27 (ver foto 3).

La posición del individuo fue de cubito dorsal, los brazos cruzados sobre el pecho, las piernas flexionadas hacia el cuerpo, ligeramente hacia el lado izquierdo. El cráneo estuvo inclinado hacia el lado derecho, y mirando hacia el Sur. No hubo presencia de los huesos de los pies ni de las manos.

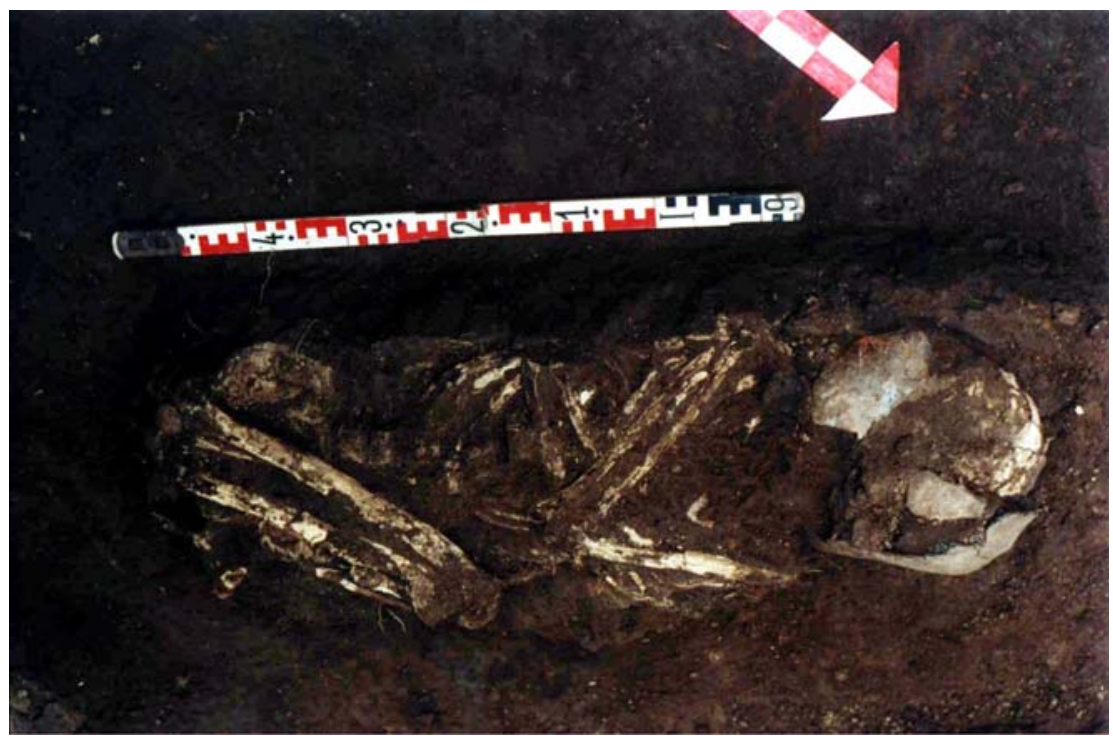

Foto 5.

Entierro (Fuente: Daniel Morales) 
- $\quad$ Contexto Funerario de Tipo Secundario: Este tipo de contexto se caracteriza porque los individuos se encuentran desarticulados y generalmente incompletos.

Este tipo de Entierro fue el que predominó en toda el área excavada, observándose, sin embargo, variabilidad en cuanto al tratamiento del individuo, es decir, no hubo una manera única en cuanto al ordenamiento del esqueleto desarticulado e incompleto. En algunos casos los restos del individuo fueron colocados directamente sobre el suelo y luego fueron cubiertos con grandes fragmentos de cerámica. En otros casos los restos óseos fueron colocados al interior de una urna de cerámica, muchos de los cuales presentaban una tapa consistente en otra vasija de cerámica. Así mismo la disposición de los restos óseos al interior de las urnas no presentaban un ordenamiento único, sino que hubo también variabilidad.

Hubo contextos donde el cráneo estuvo presente junto a otros huesos.

Se registraron contextos donde se observó la presencia de dos cráneos con algunos huesos largos incompletos.

Asimismo, se registraron contextos donde no hubo presencia del cráneo, sólo de huesos largos y contextos donde sólo hubo fragmentos de hueso muy pequeños por lo que no se pudo identificar a qué parte del cuerpo pertenecían.

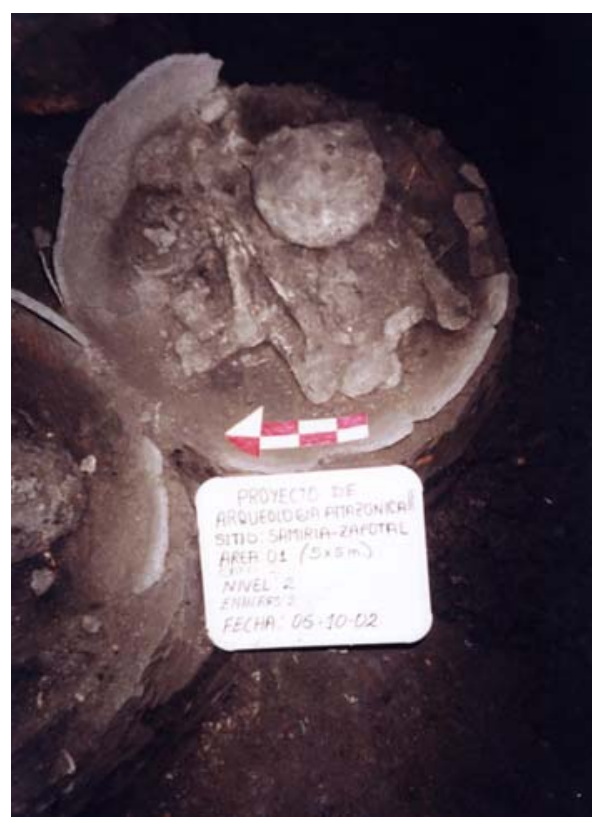

Foto 6.

Entierro Secundario $N^{0} 2$ 


\section{b) Formas de las vasijas}

Las urnas de cerámica generalmente presentaron las siguientes formas:

Forma A: Consiste en una vasija cuya mitad superior es de forma hemisférica y la mitad inferior termina en una base cónica (ver Fig. 1).

El diámetro de la boca varía entre 47 a $60 \mathrm{~cm}$., siendo el diámetro del cuerpo de mayor medida con respecto a la boca de la vasija. Decoradas en su gran mayoría con pintura roja tanto la urna como la tapa.

Forma B: Consiste en una vasija de forma hemisférica y base generalmente plana, el diámetro de la boca varía entre 34 a $60 \mathrm{~cm}$. Aquí también el diámetro del cuerpo es de mayor medida con respecto a la boca (ver Fig. 1). También estuvieron decoradas con pintura roja.

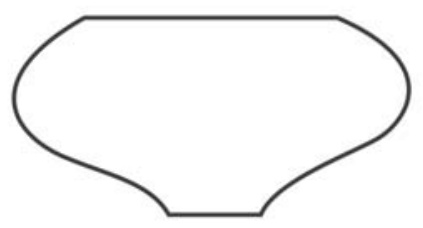

Forma A

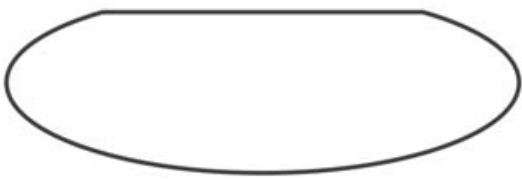

Forma B

Figura 1.

Formas de las vasijas

c) Objetos asociados a los entierros

Los objetos que fueron colocados junto al individuo como parte del ajuar funerario vienen a ser los «objetos asociados», los que pudieron haber cumplido una función de ofrenda. De todos los contextos analizados sólo dos de ellos presentaron claramente objetos asociados.

Uno de ellos fue el Entierro de tipo Secundario 14 que se encontró asociado a un piruro de cerámica colocado muy cerca al cráneo del individuo. El otro contexto fue el Entierro de tipo Primario 27, el cual se encontraba asociado a un pequeño cuenco de cerámica que cubría parte del cráneo del individuo.

Los otros contextos quizá también pudieron haber presentado objetos asociados debido a que durante la excavación se observaron algunos piruros de cerámica muy cerca de las urnas, así como cantos rodados muy pequeños (ver foto 9). 
Hubo gran variedad de piruros en cuanto a formas, tamaño y decoración: incisos, pintados y no decorados (ver fotos 7 y 8 ).

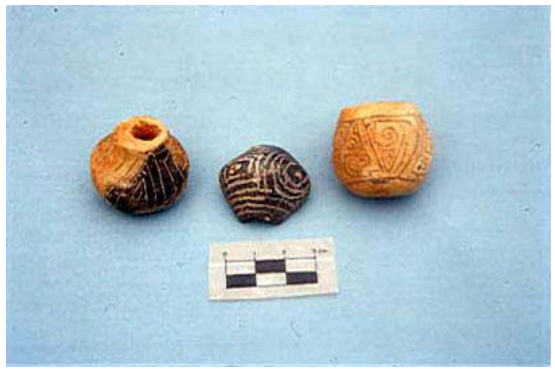

Foto 7.

Piruros decorados

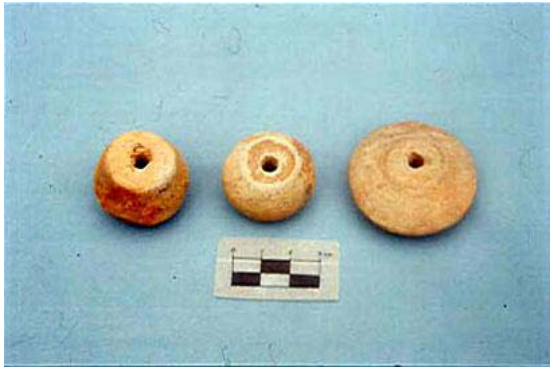

Foto 8.

Piruros no decorados (Fuente: Daniel Morales)

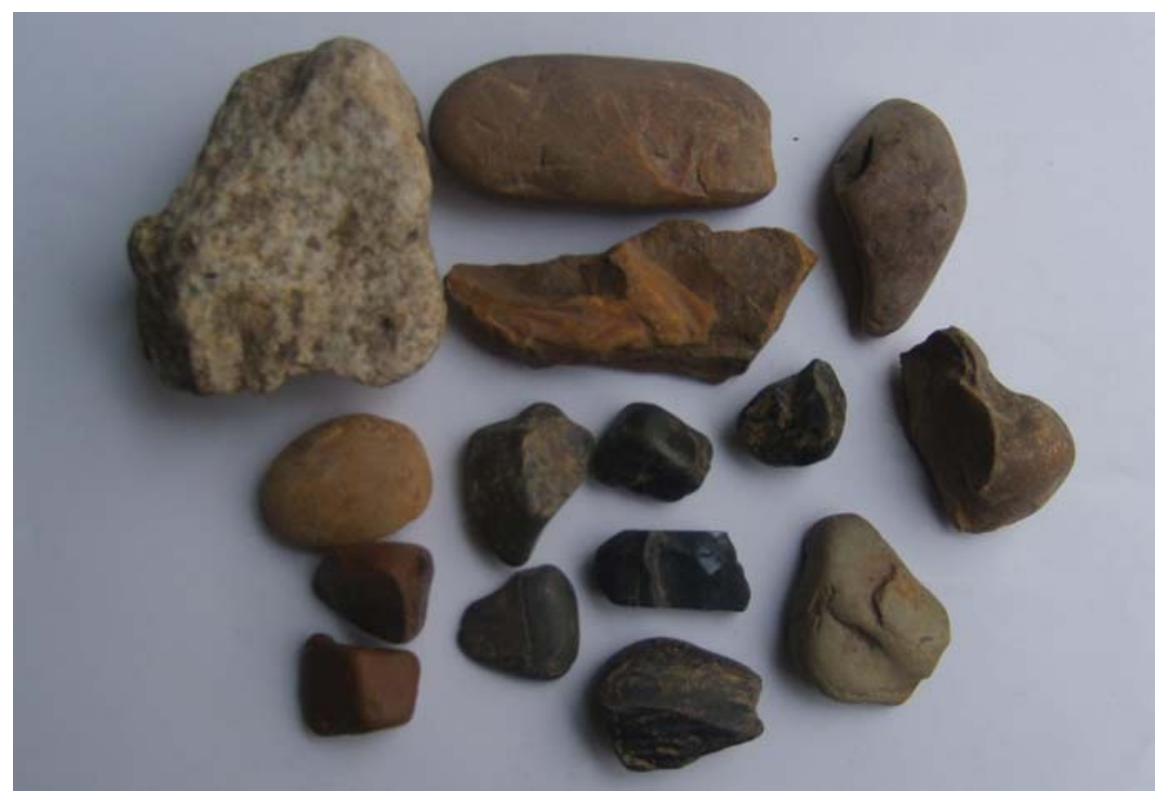

Foto 9.

Material lítico recuperado cerca de algunos entierros 


\section{Consideraciones Finales}

La información presentada en este trabajo ha reunido básicamente los datos registrados en el campo y algunos de carácter bibliográfico. Por lo que a continuación presentaremos algunas conclusiones preliminares.

Las evidencias recuperadas durante la excavación nos indican que en El Zapotal hubo áreas diferenciadas para vivienda y cementerio. Esta conclusión se basa en el hecho que dentro de las Áreas 02 y 03 no hubo presencia de ningún contexto funerario, sólo evidencias de carácter doméstico. Mientras que en el Área 01 hubo una gran concentración de contextos funerarios, los cuales se encontraban distribuidos en toda el área excavada, desde el nivel superior hasta el nivel más profundo.

La práctica del entierro primario en el nivel más profundo, y secundario en los niveles superiores nos indicarían un tipo de diferenciación cronológica. Es decir, el uso de urnas durante el entierro del individuo estaría asociado a periodos de ocupación más tardíos dentro de El Zapotal. En cambio, los enterramientos sin el uso de urnas estarían más bien relacionados a períodos más tempranos o más antiguos, y quizá a otro grupo cultural.

Las características que presentaron los contextos funerarios de tipo secundario nos estarían indicando una serie de procesos rituales en torno a las urnas funerarias por parte de los familiares del muerto. La información etnográfica presentada al inicio nos indica que los diversos grupos nativos realizaban una serie de ceremonias en torno a la urna funeraria y el cadáver antes de ser enterrado definitivamente.

De los datos de campo podemos inferir que una vez enterrada la urna definitivamente se prestó poco interés en su cuidado, estando esto evidenciado en aquellas urnas que fueron colocadas aplastando a otras.

Sobre el agrupamiento de algunas urnas en algunos espacios, podemos inferir que esto se pudo deber a algún tipo de afinidad entre los individuos allí enterrados, quizá grupos de familias. Siendo esta inferencia aún tentativa, incluso especulativa, debido a que no se han realizado análisis más profundos de los restos óseos, y para ello necesitaríamos muestras en buen estado, algo que es muy difícil de obtener en sitios como en El Zapotal, aunque no imposible.

Del registro de los objetos asociados a los entierros podemos llegar también a algunas conclusiones.

La presencia de piruros de cerámica (objetos para el hilado), nos estaría indicando que la población allí enterrada realizaba actividades relacionadas a la textilería, debido a que su presencia estuvo relacionada a los Entierros y Hallazgos, incluso dentro de la tierra excavada en cada uno de los niveles. 
Elementos de otra naturaleza como el material lítico también nos está revelando información sobre otros aspectos de ese grupo social. El material lítico en esta parte del territorio amazónico es escaso, incluso inexistente. Entonces, el hecho de su presencia en El Zapotal, en este caso en forma de cantos rodados muy pequeños y acumulados en un determinado espacio dentro del área de entierros, nos indica que estos materiales fueron muy especiales dentro de este grupo social, y que para obtenerlo tuvieron que relacionarse con grupos que habitaban regiones donde este material existe, probablemente ejerciendo alguna suerte de intercambio para su obtención. Esto implica tener que movilizarse fuera de su territorio, y asimismo llevar materiales para el intercambio. Quizá la gente de El Zapotal estaría produciendo tejidos no sólo para su uso, sino también para el intercambio.

El material lítico también estaría relacionado con otra actividad, como la alfarería, la cual fue muy abundante en las tres áreas excavadas. Quizá habrían servido como pulidores o alisadores en el proceso de manufactura de la cerámica. También la cerámica habría sido otro bien cultural de intercambio.

Agradecimientos

Quiero expresar mi más profundo agradecimiento al Lic. Daniel Morales por haberme permitido participar en el Proyecto de Arqueología Amazónica que él dirige. Siendo el presente artículo resultado de dicha participación.

Asimismo, mi agradecimiento a los pobladores de la comunidad de San José de Samiria por su hospitalidad y colaboración durante el trabajo de campo.

Finalmente, quisiera agradecer al Instituto de Investigaciones Históricos Sociales de la Facultad de Ciencias Sociales de la Universidad Nacional Mayor de San Marcos por el otorgamiento de una beca económica que hizo posible mi traslado al lugar de investigación. 
Bibliografía

ABURTO, Carlos

1999 «Políticas y métodos de evangelización en Maynas durante el siglo XVIII: definiendo los elementos de la cultura misionera». En Un Reino en la Frontera. Las misiones jesuitas en la América colonial. Pág. 77-96. Perú.

CARVAJAL, Fray Gaspar de

1955 Relación del descubrimiento del famoso río grande que desde su nacimiento hasta el mar descubrió el capitán Orellana en unión 50 hombres. Publicado por José Toribio Medina y por Antonio Ballesteros.

DEL BUSTO, José A.

S/f El descubrimiento del Amazonas. Ediciones Librería Studium. Lima-Perú.

FIGUEROA, Francisco de; ACUÑA, Cristóbal de, y otros.

1986 Informes de Jesuitas en el Amazonas 1660-1684. En Monumenta Amazónica. Iquitos-Perú.

FUNG PINEDA, Rosa

1982 «Notas y Comentarios sobre el sitio de Valencia en el Río Corrientes». En Amazonía Peruana, Vol. IV, N 7, pág. 99-137.

KAULICKE, Peter

1997 Contextos Funerarios de Ancón. Esbozo de una síntesis analítica. Pontificia Universidad Católica del Perú Fondo Editorial.

MORALES, Daniel

2002 «Contactos entre cocamas y shipibos: un acercamiento arqueológico en la Amazonía peruana.» Investigaciones Sociales, N 10, UNMSM, Lima -Perú.

NEGRO, Sandra

1999 «Maynas, una misión entre la ilusión y el desencanto». En Un Reino en la Frontera. Las misiones jesuitas en la América colonial. Pág. 269-299. Perú.

RUIZ, Eva

2005 «Evidencias arqueológicas de contextos funerarios en el sitio de San José de Samiria, Loreto». En Boletín de Estudios Amazónicos de la Unidad de Post Grado de Ciencias Sociales de la UNMSM, Maestría en Estudios Amazónicos, Año I, No 1 .

STOCKS, Anthony

1981 Los Nativos Invisibles. Notas sobre la historia y realidad actual de los Cocamilla del Río Huallaga, Perú. CAAAP, Lima-Perú. 